\title{
Survey Measures of Web-Oriented Digital Literacy
}

\author{
ESZTER HARGITTAI \\ Northwestern University
}

This article presents survey measures of web-oriented digital literacy to serve as proxies for observed skill measures, which are much more expensive and difficult to collect for large samples. Findings are based on a study that examined users' digital literacy through both observations and survey questions, making it possible to check the validity of survey proxy measures. These analyses yield a set of recommendations for what measures work well as survey proxies of people's observed web-use skills. Some of these survey measures were administered on the General Social Survey 2000 and 2002 Internet modules, making the findings relevant for the use of existing large-scale national data sets. Results suggest that some composite variables of survey knowledge items are better predictors of people's actual digital literacy based on performance tests than are measures of users' self-perceived abilities, a proxy traditionally used in the literature on the topic.

Keywords: methods; surveys; measures; skill; web use; digital literacy, internet, online behavior

A

$\mathrm{n}$ increasing body of literature on how people are incorporating the Internet into their everyday lives (Fallows, 2004; Howard \& Jones, 2003; Wellman \& Haythornthwaite, 2002) and in particular on how online behavior differs across different segments of the population (DiMaggio, Hargittai, Celeste, \& Shafer, 2004) exists. As diffusion has spread across the population, a growing number of scholars have been looking at differences in online behavior among web users in addition to simply exploring differences in access statistics (Mossberger, Tolbert, \& Stansbury, 2003, Howard, Rainie, \& Jones 2001; van Dijk, 2005). Much of such research relies on survey data about people's online activities. Survey measures are helpful because they allow for the collection of data from relatively large sample sizes, making possible various quantitative analyses and the potential generalizability of the findings for a larger population group. However, some questions are hard to assess through survey questions. One such area concerns information about people's digital literacy.

An existing line of research has focused on people's computer skills (e.g., Dutton \& Anderson, 1989; Shashaani, 1994), with some emphasis on Internet skills in recent years (Hargittai, 2002b, 2003; Mossberger et al., 2003). However, most of the existing literature is based on people's perception of their computer skills, often referred to as self-efficacy (Bandura, 1977), instead of on people's actual abilities as measured through observations or

AUTHOR'S NOTE: I would like to thank Paul DiMaggio, Scott Lynch, and Peter Miller for helpful discussions. I am also indebted to Ron Anderson and the anonymous referees for their valuable suggestions for improving the article. Generous support from the Markle Foundation and NSF grant IIS0086143 is kindly acknowledged. The project has also been supported in part by a grant from the Russell Sage Foundation. I am also grateful to the Dan David Foundation for its support.

Social Science Computer Review, Vol. 23 No. 3, Fall 2005 371-379 DOI: $10.1177 / 0894439305275911$

(C) 2005 Sage Publications 
survey items that measure users' actual knowledge of computer- and Internet-related terms and functions.

This article contributes to the literature on refined measures of web use and digital literacy studies in particular by presenting possible survey measures of people's online skills derived from measures about the actual online skills of users assessed through performance tests. Findings are based on the online abilities of 100 randomly selected Internet users in a New Jersey county. Using data on both people's actual web-use skills and survey questions measuring their knowledge of Internet-related items, we can determine whether identical survey questions administered on the General Social Survey (GSS) Internet modules in 2000 and 2002 can be used as a proxy for people's online skills. On the basis of these analyses, I recommend the creation of index variables for both GSS 2000 and GSS 2002 as proxies for digital literacy measures. I also make recommendations about which survey questions should be administered on future surveys for optimal composite measures of web-oriented digital literacy.

As Internet use diffuses to an increasing portion of the population, we need measures beyond simple access statistics for a refined understanding of potential inequalities stemming from differentiated Internet use. A focus on variation in digital literacy allows us to see what segments of the population may be best poised to benefit from the medium. As research has shown, merely having access to an Internet-connected machine does not result in informed users (Hargittai, 2003). If some people are unable to find information online while an increasing number of services relevant to daily life become easiest to access on the web (e.g., financial services, product information, government forms), then the segment of the population with low digital-literacy levels will become increasingly disadvantaged in our digital world.

\section{In-Depth Measures of Online Skill}

I draw on data from a project I conducted from 2001 to 2002 on people's web-use skills. I defined skill as a user's ability to locate content on the web effectively and efficiently. I gathered data on 100 randomly selected web users' online skills using in-person observations and in-depth interviews. Participants performed online tasks in a research setting. All of their online actions were recorded and later analyzed to see whether they could locate various types of content online and how long they took to do so. Hargittai (2002a, 2004a) describes the methodology in more detail. The in-person observations of people's online browsing behavior resulted in two measures of online skill: the percentage of eight tasks completed successfully (effectiveness) and the amount of time spent on the eight tasks (efficiency).

Participants looked for information on (a) job or career opportunities; (b) a site that compares different presidential candidates' views on abortion; (c) a used car for purchasing; (d) tax forms; (e) information about local cultural events (movie time listings, theatre shows); (f) music to listen to online; (g) children's art; and (h) a museum's or gallery's web site. See Hargittai (2003) for copies of all study instruments.

\section{Survey Measures of Digital Literacy}

In addition to looking for various types of content online, participants were also presented with survey questions to measure selected aspects of their Internet-related knowledge. In sum, four different types of measures were collected about digital literacy levels: (a) four yes or no self-report questions about digital literacy; (b) 38 five-point (self-reported) ratings of degree of understanding of digital literacy-related items; (c) 37 multiple choice tests of digi- 
tal literacy (subsample only); and (d) an overall (self-report) rating of Internet skill. These measures are presented in detail, including the exact wording of the survey questions, in Appendix A.

\section{Digital Literacy Measures on the GSS}

Some of the self-report questions from this study were replicated on the GSS 2000 and GSS 2002 Internet modules (the items included in GSS 2002 were based on preliminary results from this project). These items are presented in Appendix B.

The descriptive statistics suggest that respondents in the project on which this article draws tended to be somewhat (a few percentage points) more knowledgeable about Internetrelated terms than were those who participated in the GSS (in both 2000 and 2002). However, the overall ranking of items is similar in the two studies. Terms that most people knew well in the in-depth study correspond to the items that most people also knew in the GSS, and the least familiar items were the same in both samples. These similarities suggest that findings about the survey measures based on the in-depth study sample are generalizable to use of the GSS Internet modules.

\section{The Validity of Self-Reported Ratings of Digital Literacy Items}

To test the validity of self-reported scores on digital literacy items, a subset of respondents answered multiple-choice questions about 37 of the terms. They were presented with five options from which one was the correct response. Table 1 presents the Pearson's and polychoric correlation coefficients for the 37 self-reported ratings and the multiple-choice question results. I use both coefficients because the Pearson's correlation coefficient tends to underestimate the relationship of variables when used for ordinal-level data (Lynch, 1999). ${ }^{2}$ The coefficients in the table indicate that there are statistically significant correlations among the majority of the measures. Three variables did not show any variance on the multiple-choice measures, making it impossible to calculate meaningful correlations among those measures and self-reported levels of understanding. Nonetheless, for the majority of the variables, the self-reported knowledge measure is a good indication of people's actual knowledge of the terms.

\section{The Relationship Between Behavioral and Survey Measures of Digital Literacy}

I calculated the Pearson's correlation coefficients among the self-reported ratings and the two items measuring actual ability: percentage of tasks successfully completed (effectiveness) and amount of time spent on the eight tasks (efficiency). The third and fourth columns in Table 1 present the results of these analyses for the entire sample. Items that were replicated on the GSS Internet modules are highlighted in bold.

The signs of the coefficients are in the expected direction. For percentage of tasks successfully completed, the correlation coefficients are positive, suggesting that understanding the various computer- and Internet-related terms is positively correlated with users' ability to find content online. The negative coefficients for time spent on tasks shows that those with a better understanding of computer and Internet terms took less time to look for information online. In the majority of cases, the coefficients are statistically significant for both outcome skill measures. This suggests that the self-reported ratings of digital literacy items may be 
TABLE 1

Pearson's and Polychoric Correlation Coefficients of Self-Reported Ratings and Multiple-Choice Tests

\begin{tabular}{|c|c|c|c|c|}
\hline Digital Literacy Items & $\begin{array}{l}\text { Pearson's } \\
\text { Correlation } \\
\text { Coefficient }\end{array}$ & $\begin{array}{l}\text { Polychoric } \\
\text { Correlation } \\
\text { Coefficient }\end{array}$ & $\begin{array}{l}\text { Correlation } \\
\text { With Successful } \\
\text { Completion } \\
\text { of Tasks }\end{array}$ & $\begin{array}{l}\text { Correlation } \\
\text { With Total } \\
\text { Time Spent } \\
\text { on } 8 \text { Tasks }\end{array}$ \\
\hline Download $^{\text {ac }}$ & - & - & $.5272^{\star \star \star}$ & $-.4392^{\star \star \star}$ \\
\hline Advanced search ${ }^{\mathrm{ac}}$ & - & - & $.5110^{\star \star \star}$ & $-.4261^{\star \star \star}$ \\
\hline Preference setting $^{a}$ & $.5052^{\star \star \star}$ & .982514 & $.4730^{\star \star \star}$ & $-.4215^{\star \star \star}$ \\
\hline Newsgroup $^{a}$ & $.5640^{\star \star \star}$ & .871793 & $.4710^{\star \star \star}$ & $-.4680^{\star \star \star}$ \\
\hline $\mathrm{PDF}^{\mathrm{a}}$ & $.6866^{\star \star \star}$ & .855970 & $.4647^{\star \star \star}$ & $-.4186^{\star \star \star}$ \\
\hline Refresh or reload ${ }^{\mathrm{a}}$ & $.6912^{\star \star \star}$ & .762428 & $.4509^{\star \star \star}$ & $-.4739^{\star \star \star}$ \\
\hline MP3 $^{\mathrm{a}}$ & $.5582^{\star \star \star}$ & .717611 & $.4112^{\star \star \star}$ & $-.4265^{\star \star \star}$ \\
\hline Upload $^{c}$ & - & - & $.4762^{\star \star \star}$ & $-.3771^{\star \star \star}$ \\
\hline E-zine & $.6660^{\star \star *}$ & .865540 & $.3323^{\star \star *}$ & $-.3729^{\star \star \star}$ \\
\hline Banner ad & $.7289 * \star \star$ & .895455 & $.4332^{\star \star \star}$ & $-.3342^{\star \star \star}$ \\
\hline.$g o v$ & $.4915^{\star \star \star}$ & .887191 & $.4310^{\star \star \star}$ & $-.3309^{\star \star \star}$ \\
\hline HTML & $.5231^{\star * \star}$ & .601987 & $.4227^{\star \star \star}$ & $-.4334^{\star \star \star}$ \\
\hline Search engine ${ }^{c}$ & - & - & $.4186^{\star \star \star}$ & $-.2392^{\star}$ \\
\hline JPG & $.7006^{\star \star \star}$ & .853337 & $.4105^{\star \star \star}$ & $-.4059^{\star \star \star}$ \\
\hline Shareware & $.6726^{\star * \star}$ & .868788 & $.4099 * \star \star$ & $-.3053^{\star \star \star}$ \\
\hline Browser $^{b}$ & - & - & .4050 *** & $-.2965^{\star \star \star}$ \\
\hline Frames & $.6661^{\star \star \star}$ & .875697 & $.4014^{\star \star \star}$ & $-.3695^{\star \star \star}$ \\
\hline Remote login & $.5909^{\star \star \star}$ & .770501 & $.3721^{\star \star \star}$ & $-.3718^{\star \star \star}$ \\
\hline Spam & $.5895^{\star \star \star}$ & .844139 & $.3637^{\star \star \star}$ & $-.3511^{\star \star \star}$ \\
\hline Boolean expression & $.6887^{\star \star \star}$ & .865298 & $.3512^{\star \star \star}$ & $-.2058^{\star *}$ \\
\hline ISP & .2401 & .728378 & $.3455^{\star \star \star}$ & $-.3041^{\star \star \star}$ \\
\hline bcc option in email & $.7915^{\star \star \star}$ & .879233 & $.3412^{\star \star \star}$ & $-.3681^{\star \star \star}$ \\
\hline Cookie & $.5833^{\star \star \star}$ & .864487 & $.3197^{\star \star \star}$ & $-.3494^{\star \star \star}$ \\
\hline Natural language & .2366 & .769852 & $.3024^{\star \star \star}$ & -.1625 \\
\hline Mirror site & $.7398^{\star \star \star}$ & .891701 & $.2915^{\star \star \star}$ & $-.2267^{\star}$ \\
\hline Flaming & $.8224^{\star \star \star}$ & .892490 & $.2772^{\star \star}$ & $-.3220^{\star \star \star}$ \\
\hline Message thread & $.7203^{\star \star \star}$ & .807312 & $.2766^{\star \star}$ & $-.3034^{\star \star \star}$ \\
\hline XML & $.5704^{\star \star \star}$ & .849796 & $.2707^{\star \star \star}$ & $-.2866^{\star \star \star}$ \\
\hline Meta-search engine & $.5406^{\star \star \star}$ & .888293 & $.2687^{\star \star \star}$ & -.1905 \\
\hline Usenet & $.5284^{\star \star \star}$ & .604538 & $.2494^{\star}$ & $-.2525^{\star}$ \\
\hline Server & .1542 & .210150 & $.2453^{*}$ & -.1675 \\
\hline Open attachment $^{\mathrm{C}}$ & - & - & $.2381^{*}$ & -.1052 \\
\hline Click-through & $.6198^{\star \star \star}$ & .760315 & $.2289^{\star}$ & $-.2128^{\star}$ \\
\hline Image map & $.6648^{\star \star \star}$ & .759624 & $.2247^{*}$ & $-.2773^{\star \star}$ \\
\hline Proximity operators & $.4559^{\star \star}$ & .586734 & $.2159^{*}$ & -.0277 \\
\hline Meta-tag & $.7665^{\star \star \star}$ & .911197 & $.2012^{\star}$ & -.1867 \\
\hline Weblog ${ }^{\mathrm{b}}$ & - & - & $.2004^{\star}$ & -.1449 \\
\hline DNS parking & $.7590^{\star \star \star}$ & .901940 & .1858 & -.1636 \\
\hline Modem ${ }^{b}$ & - & - & .1490 & -.1085 \\
\hline P3P & $.7235^{\star \star \star}$ & .999986 & .1447 & -.1692 \\
\hline Filtering software & .2770 & .486559 & .1379 & $-.3090^{\star \star \star}$ \\
\hline Spider & $.8585^{\star \star \star}$ & .926497 & .0903 & $-.2157^{\star}$ \\
\hline
\end{tabular}

NOTE: Pearson's correlation coefficients and polychoric correlation coefficients are for five-point selfreported ratings and multiple-choice measures of digital literacy items. Pearson's correlation coefficients are for relationships among survey items and both successful completion of tasks and total time spent on eight tasks. Items replicated on the General Social Survey are highlighted in bold.

a. These items are included in the proposed best index.

b. No measure is available because no variance was observed in the responses to the multiple-choice question.

c. No multiple-choice questions were asked on the survey to test the validity of these items.

${ }^{*} p<.05 ;{ }^{* *} p<.01 ;{ }^{* \star *} p<.005$. 
used as a proxy for actual skill measures. The next step is calculating the optimal index for measuring digital literacy using survey questions.

\section{Composite Measures of Digital Literacy}

Based on the above findings about the relationship of survey and actual measures of online skill, I recommend creating a composite variable for measuring web-oriented digital literacy using survey questions. Using information from the coefficients presented in Table 1 , I created a composite index excluding those knowledge items, which exhibited low correlations with the outcome variables. This new index variable yields correlation coefficients of $.573(p=.000)$ and $-.540(p=.000)$ for successful completion of all tasks and for total time searching, respectively. This new variable is the sum of the self-reported ratings of the following seven items: MP3, preference setting, refresh or reload, newsgroup, PDF, advanced search, and download. This is the best possible index based on the findings from the study. The index has a Cronbach's $\alpha$ of 89 .

Using the GSS, we are limited to questions asked on the surveys in 2000 and 2002, so I discuss those separately. The composite variables I present here in the case of both of these surveys is based on the self-rated items that exhibited the highest and most statistically significant correlations with actual measures of skill.

For GSS 2000, a composite of the download and upload variables may be used as a proxy for skill. In the user study discussed in this article, the correlation of this index variable with actual measures of skill is higher than any individual correlation coefficient at $.5511(p=$ $.000)$ for successful completion of all tasks and $-.4475(p=.000)$ for total time spent on the eight tasks. The composite variable's Cronbach's $\alpha$ for the study sample is .77 and for the GSS sample is .65.

For GSS 2002, an index variable constructed of the advanced search, preference setting, and newsgroup variables yields the best proxy for actual skill. ${ }^{3}$ Based on data from the study reported here, the correlation of this constructed index variable with actual measures of skill is higher than any individual correlation coefficient at $.5579(p=.000)$ for successful completion of all tasks and $-.5061(p=.000)$ for total time spent on the eight tasks. The Cronbach's $\alpha$ for the variables included in this index is .83 for the New Jersey study sample and .76 for the national GSS sample.

\section{Survey Measures of Digital Literacy as Predictors of Actual Online Skill}

Most existing research on people's computer-use skill, a focus more common than Internet-use skills in the literature, draws on information about people's self-perceived skills instead of measures of actual abilities. For comparison purposes, respondents in this study were also asked to rate their self-perceived Internet skill level. The mean of this measure is 2.88 in the study sample $(S D=.73)$. Another possible proxy for skill may be the amount of time people spend online. Those who spend more time online have more opportunity to refine their online abilities. A similar argument may be made for number of years one has been an Internet user. Over time, people may well pick up skills and improve their digital literacy. I consider the predictive power of these variables on actual skill as well.

To test the power of the proposed composite measures based on people's self-rated understanding of digital literacy items, I compare the predictive power of the more traditional selfperceived skill measure and the Internet time use measures to the predictive power of the new constructs on actual skill. In Table 2, I present the results of the various survey measures' predictive power with respect to actual skill. The first row shows the adjusted $R^{2}$ for amount of 
TABLE 2

The Predictive Power of the Various Survey Measures of Actual Skill

\begin{tabular}{lc}
\hline \hline Survey Measures & Actual Skill Measure Adjusted $R^{2}$ \\
\hline Time spent on web weekly & .048 \\
Years using the Internet & .114 \\
Self-perceived skill & .239 \\
General Social Survey (GSS) 2000 index & .297 \\
GSS 2002 index & .304 \\
Seven-item best index & .321 \\
\hline
\end{tabular}

time spent on the web as a predictor of actual skill, whereas the second row shows the result for number of years a respondent has been a user. The third row displays the result of the selfperceived skill measure regressed on the actual skill measure. The fourth and fifth rows show the results of the indexes created from the variables available on the GSS 2000 and 2002 Internet modules, respectively, regressed on the actual skill measure. ${ }^{4}$ Finally, the last row shows the predictive power of the seven-item composite variable based on the most highly correlated survey measures of skill. This is the best predictor of skill, and thus the recommendation from this study is that the seven items that make up this scale should be included in future surveys as a measure of people's web-oriented digital literacy.

\section{Conclusion}

As the web evolves, more and more information is available on the network to users. Search and classification services continue to develop and evolve to help users deal with the demands of the increasingly vast amounts of available information and to help users find material of interest to them. Although these services have certainly made online content more accessible to some, their mere existence does not guarantee that people will be able to navigate efficiently the literally billions of pages that make up the web (Hargittai, 2004b; Rieh, 2004; Spink, Wolfram, \& Jansen, 2001). Users differ with respect to their awareness of various search engines and the optimal ways to use them (Hargittai, 2003). Today's search engines are still not well equipped to deal with simple queries that contain no more than one word, yet the majority of queries on search engines do not include more refined information (Spink et al., 2001; Spink, Jansen, Wolfram, \& Saracevic, 2002). This limits their utility for numerous users and limits the ways in which these users may benefit from the medium.

As the Internet spreads to an increasing portion of the population and as online services start permeating more and more parts of people's daily lives, nuanced measures of Internet use will gain importance for research on the social implications of information technologies. The validity of survey measures is an important challenge for social scientists. In this article, I contribute to the literature on Internet use and methodology by proposing a survey measure of web-oriented digital literacy that is based on verifying the validity of the measures derived from their relationship with actual skill measures. 
Given that some of these measures were administered on the GSS Internet modules in 2000 and 2002, researchers using those publicly available data sets will be able to incorporate these nuanced measures of Internet use into the analyses of large-scale national databases. ${ }^{5}$ Because the items identified here as important predictors of actual skill are measured on a five-point scale, their inclusion on future surveys should be possible with relatively little effort, as compared to refined user studies. Yet, they will yield more reliable estimates of people's actual skills than the currently dominant survey measure of self-perceived user skill allows.

\section{APPENDIX A}

1. Yes or no self-reports of digital literacy (4).

DOWNLOAD - Do you know how to download a file from the World Wide Web to your computer? [17\% no]

UPLOAD—Do you know how to send a file that is on your computer's hard drive to someone using another computer? [26\% no]

OPENATT - Do you know how to open an attachment someone sent you via email? [4\% no]

SRCHENGN1-Do you know the name of any search engines? [13\% no]

2. Five-point self-reported ratings of digital literacy items (38). ${ }^{\mathrm{a}}$

How familiar are you with the following Internet-related items? Please choose a number between 1 and 5 where 1 represents having "no understanding" and 5 represents having "a full understanding" of the item. [none, little, some, good, full]

Modem, Browser, Server, ISP, HTML, "bcc" option in email, Flaming, Spam, Spider, Boolean expression, MP3, JPG, XML, Meta-search engine, Natural language, Proximity operators, .gov ("dot gov"), Banner ad, Weblog, Usenet, Message thread, Filtering software, Cookie, DNS parking, Mirror site, P3P, Click-through, Image map, E-zine, Meta-tag, Frames, Shareware, Preference setting, Remote login, Refresh/Reload, Newsgroup, PDF

3. Multiple-choice tests of the same digital literacy items (37) above, administered on random $36 \%$ of participants. ${ }^{\mathrm{b}}$

Please choose the correct response to all of the following multiple choice questions.

What is [digital literacy item]?

What does [digital literacy item] stand for? [used for acronyms]

4. Self-reported rating of Internet skill. Users were asked to answer the following question measured on a five-point scale (not at all skilled, not very skilled, fairly skilled, very skilled, expert).

"In terms of your Internet skills, do you consider yourself to be ...."

[On a scale of 1 to 5, the mean self-perceived skill level is 2.88 in the sample; $S D=.73$ ]

NOTE: Descriptive statistics are presented in brackets.

a. Exact wording of the question is presented for the items.

b. One of the 38 items (advanced search) was accidentally omitted from the multiple-choice section of the survey, so it is not possible to run a validity check on that item. 


\section{APPENDIX B}

General Social Survey (GSS) 2000-Yes or no self-reports of digital literacy

DOWNLOAD - Do you know how to download a file from the World Wide Web to your computer? [20\% no]

UPLOAD - Do you know how to send a file that is on your computer's hard drive to someone using another computer? [31\% no]

GSS 2002-Three-point self-reported ratings of digital literacy items ${ }^{\mathrm{a}}$

Are you very familiar, somewhat familiar or not familiar with the following Internet terms:

ADVSRCH—Advanced Search [23\% not familiar]

MP3-MP3 [47\% not familiar]

EZINES-E-zines [81\% not familiar]

PREFSETS-Preference Settings [27\% not familiar]

NEWSGRPS-Newsgroups [40\% not familiar]

NOTE: Descriptive statistics are presented in brackets.

a. Exact wording of the question is presented for the items.

\section{NOTES}

1. Undoubtedly, there are numerous online actions one can consider when measuring web-use skill. Here, I focused on the aspect of information retrieval instead of person-to-person communication because many forms of group discussion are also contingent upon the ability to find relevant groups with which to discuss topics.

2. I thank Scott Lynch for giving me access to his program to estimate the polychoric correlations.

3. Although the variable EZINE also exhibited statistically significant correlation, the actual level of correlation was considerably lower than the figures for the other three variables, making the value of the construct weaker than that of individual variables, and thus EZINE is not included in the index.

4. I created a composite variable including all of the digital literacy items available on the General Social Survey 2002 Internet module. The Cronbach's $\alpha$ for these variables is .79, which is slightly higher than the $\alpha$ for the three variables in the construct. However, when checking the predictive power of this larger index variable, the results suggest that it is not as a good a predictor of the measures resulting from the performance tests as is the smaller construct. The adjusted $R^{2}$ for the 5 -item scale is .28, suggesting that the index variable that only contains the three most highly correlated variables is a better proxy for actual skill than is a sum of all available variables.

5. Undoubtedly, some knowledge about Internet-related terms will change over time across the population as particular features and services become increasingly well-known by users. Nonetheless, because the study reported in this article was administered within the same timeframe as the General Social Survey (GSS) Internet modules, findings from this study can be generalized to use of the GSS.

\section{REFERENCES}

Bandura, A. (1977). Self-efficacy: Toward a unifying theory of behavioral change. Psychological Review, 84, 191215.

DiMaggio, P., Hargittai, E., Celeste, C., \& Shafer, S. (2004). Digital inequality: From unequal access to differentiated use. In K. Neckerman (Ed.), Social inequality (pp. 355-400). New York: Russell Sage.

Dutton, W. H., \& Anderson, R. E. (1989). Computers and literacy: Differing perspectives in the social sciences. Social Science Computer Review, 7, 1-6.

Fallows, D. (2004). The Internet and daily life. Washington, DC: Pew Internet and American Life Project.

Hargittai, E. (2002a). Beyond logs and surveys: In-depth measures of people's Web use skills. Journal of the American Society for Information Science and Technology Perspectives, 53, 1239-1244.

Hargittai, E. (2002b). Second-level digital divide: Differences in people's online skills. Retrieved March 4, 2005, from http://www.firstmonday.org/issues/issue7_4/hargittai/index.html 
Hargittai, E. (2003). How wide a Web? Inequalities in accessing information online. Unpublished doctoral dissertation, Princeton University, Princeton, NJ.

Hargittai, E. (2004). Classifying and Coding Online Actions. Social Science Computer Review, 22, 210-227.

Hargittai, E. (2004). Life beyond Google. Retrieved March 4, 2005, from http : / / news . b bc . co . uk/ 1/hi / technology/3601371.stm

Howard, P. E. N., \& Jones, S. (2003). Society online. Thousand Oaks, CA: Sage.

Howard, P.E.N., Rainie, L., \& Jones, S. (2001). Days and nights on the internet: The impact of a diffusing technology. American Behavioral Scientist,45, 383-404.

Lynch, S. (1999). Bayesian estimation of polychoric and polyserial correlations via Markov chain Monte Carlo simulation algorithms: A simulation study comparing posterior mean and maximum likelihood estimators. Durham, NC: Institute of Statistics and Decision Sciences, Duke University.

Mossberger, K., Tolbert, C. J., \& Stansbury, M. (2003). Virtual inequality: Beyond the digital divide. Washington, DC: Georgetown University Press.

Rieh, S. Y. (2004). On the Web at home: Information seeking and Web searching in the home environment. Journal of the American Society for Information Science and Technology, 55, 743-753.

Shashaani, L. (1994). Gender differences in computer experience and its influence on computer attitudes. Journal of Educational Computing Research, 11, 347-367.

Spink, A., Jansen, B. J., Wolfram, D., \& Saracevic, T. (2002). From e-sex to e-commerce: Web search changes. IEEE Computer, 35, 107-109.

Spink, A., Wolfram, D., \& Jansen, B. J. (2001). Searching the Web: The public and their queries. Journal of the American Society for Information Science and Technology, 52, 226-234.

van Dijk, J. (2005). The Deepening Divide. London: Sage.

Wellman, B., \& Haythornthwaite, C. (2002). The Internet in everyday life. Oxford, UK: Blackwell.

Eszter Hargittai is an assistant professor of communication studies and sociology, and faculty fellow in the Institute for Policy Research at Northwestern University. She may be contacted at sScore05@ webuse.org. 